\title{
Investigation of stand-off distance effect on structure, adhesion and hardness of copper coatings obtained by the APS technique
}

\author{
Goudarzi Masoumeh $^{1} \cdot$ Saviz Shahrooz ${ }^{1} \cdot$ Ghoranneviss Mahmood $^{1} \cdot$ Salar Elahi Ahmad ${ }^{1}$
}

Received: 4 August 2017 / Accepted: 25 February 2018/Published online: 26 March 2018

(C) The Author(s) 2018

\begin{abstract}
The outbreak of the disease and infection in the hospital environment and medical equipment is one of the concerns of modern life. One of the effective ways for preventing and reducing the complications of infections is modification of the surface. Here, the handmade atmospheric plasma spray system is used for accumulating copper as an antibacterial agent on the 316L stainless steel substrate, which applies to hospital environment and medical equipment. As a durable coating with proper adhesion is needed on the substrate, the effect of stand-off distance (SOD) which is an important parameter of the spray on the microstructure, the hardness and adhesion of the copper coating on the $316 \mathrm{~L}$ stainless steel were investigated. The structure and phase composition of copper depositions were investigated using scanning electron microscopy and $\mathrm{X}$-ray diffraction. The adhesion and hardness of depositions are evidenced using the cross cut tester and Vickers hardness tester, respectively. The findings confirm that the voids in the coatings increase with increasing SOD, which leads to decreasing the hardness of coatings and also the adhesion strength between depositions and substrate. In addition, by increasing the SOD, the oxygen content and the size of grains in the lamellae (fine structure) of coatings also increase.
\end{abstract}

Keywords Atmospheric plasma spray · Copper · Stand-off distance $\cdot$ Fine structure $\cdot$ Hardness and adhesion strength

\section{Introduction}

The properties of depositions depend on spray methods $[1,2]$. In recent years, the plasma spray technique is used for deposition of different coatings [3, 4]. The performance of a plasma spray system depends on the design of torch, type and rate of plasma gas, plasma power and suchlike. The structural modification of the plasma torch can increase the power of plasma, which leads to more hardness of the coatings [5]. By adding helium or hydrogen gas to plasma gas, the power of plasma increases resulting in increase of coating hardness [6]. The bond between the splats inside the depositions and layer structure of coatings is the factor which defines the features of coatings achieved

Saviz Shahrooz

azarabadegan@gmail.com

1 Plasma Physics Research Center, Science and Research Branch, Islamic Azad University, Tehran, Iran by the plasma spray method [7]. The temperature of particles plays an important role in the hardness of depositions [8]. Roughness and temperature of substrates can improve solidification of copper droplets and modify the properties of depositions obtained by the plasma spray technique $[9,10]$. The large diameter of the nozzle can improve cohesion between the lamellae in the coatings, because the dwelling time of particles in plasma torch increases [11]. The depositions of nickel-based alloy formed by plasma spray under low power may have certain features comparable to depositions formed by conventional plasma spray [12].

\section{Methods}

The substrate is the $316 \mathrm{~L}$ stainless steel plate with a thickness of $2 \mathrm{~mm}$, which is sand blasted prior to covering and it is cut into $20 \times 20 \mathrm{~mm}^{2}$ pieces. The purity of copper powder is $99.9 \%$ and the particles size is less than $20 \mu \mathrm{m}$ (from 4.54 to $19.34 \mu \mathrm{m}$ ). The particle size distribution is often characterized by the mean diameters. Using static 
light scattering analysis (SLS), the mean value of particle size is $9.13 \mu \mathrm{m}$. The copper is sprayed using the handmade atmospheric plasma spraying (APS) system functioning at a current of $600 \mathrm{~A}$ and voltage of $30 \mathrm{~V}$, for which the schematic diagram is shown in Fig. 1a. The monitoring of the APS device consisting of the following components is manually performed. An electric discharge between the anode and cathode is provided by an electric power supply. By passing the plasma gas (argon) between them, the gas is heated and ionized, and plasma is formed. The powder is fed by a Metco powder feeder. Powder as suspension in carrying gas (argon) is injected into the plasma jet radially through a tube near the nozzle. They are melted and accelerated toward the substrate. The anode and cathode have a cooling system. When the torch works and the powder particles are sprayed, the water pump cools them [13]. The diameter and length of the torch nozzle are 4 and $40 \mathrm{~mm}$, respectively. The spray parameters collected in Table 1 including power of torch, flow rate of the plasma gas, the pressure of plasma gas and suchlike are all constant. The stand-off distances (distance between nozzle and substrate) are 150, 175, 200 and $225 \mathrm{~mm}$. The handmade experimental device during deposition is illustrated in Fig. 1b.

The crystalline spectra of coatings are observed by the STADI MP X-ray diffraction (XRD) with a filament of tungsten at voltage $40 \mathrm{kV}$ and current $30 \mathrm{~mA}$ in the presence of radiation copper anode $(\lambda=1.5402 \AA)$. The XRD spectra of the coatings are recorded in the $2 \theta$ range of $20^{\circ}-$ $80^{\circ}$ with steps 0.05 . The structures of coatings are investigated with a Philips, XL-30 back-scattering electron microscopy (BSE) and scanning electron microscopy (SEM). The coatings are pushed by a diamond indentation under a load of $100 \mathrm{~g}$ for a total time $15 \mathrm{~s}$. The average value of the three tests at different points for each of the polished coatings indicates the hardness evaluated by Vickers hardness tester $\left(\mathrm{HV}_{0.1}\right)$. In adhesion test performed by cross cut tester (TQC), some scratches are formed in
Table 1 The parameters of spray

Power of plasma, $18 \mathrm{~kW}$

Plasma gas flow rate (argon), $25 \mathrm{l} / \mathrm{min}$

Gas pressure, 0.3 MPa

Powder feed gas flow rate (argon), 15 1/min

Stand-off distances, 150, 175, 200 and $225 \mathrm{~mm}$

Cooling water rate, $10 \mathrm{l} / \mathrm{min}$

Substrate temperature, room temperature

two normal directions on the coatings. Special glue is placed on the depositions for $5 \mathrm{~min}$ and then peeled off. The adhesion strength between depositions and substrate is determined with the ASTM standard.

\section{Results and discussion}

Figure 2 shows the XRD spectra of copper coated on the 316L stainless steel substrates at the different stand-off distances. As seen in Fig. 2, the results of XRD analysis of copper-coated substrates show that samples at stand-off distances (a): $150 \mathrm{~mm}$, (b): $175 \mathrm{~mm}$ and (c): $200 \mathrm{~mm}$ contain only two phases of $\mathrm{Cu}$ and $\mathrm{Cu}_{2} \mathrm{O}$ with a cubic crystal lattice. In these coatings, the peaks at $36.52^{\circ}$, $42.43^{\circ}, 61.55^{\circ}, 73.78^{\circ}$ and $77.89^{\circ}$ are related to the copper oxide crystalline phase and the peaks formed at $43.57^{\circ}$, $50.72^{\circ}$ and $74.17^{\circ}$ angles corresponding to the copper crystalline phase.

If the sample consists of a mixture of two phases A and B where $W_{\mathrm{A}}$ and $W_{\mathrm{B}}$ are the weight percentages of these two phases, and $I_{\mathrm{A}}$ and $I_{\mathrm{B}}$ are the intensity peaks of these two phases, there is the following relation between them [14].

$\frac{W_{\mathrm{A}}}{W_{\mathrm{B}}} \propto \frac{I_{\mathrm{A}}}{I_{\mathrm{B}}}$.
Fig. 1 a The schematic of the APS system. $\mathbf{b}$ The picture of the APS device during deposition

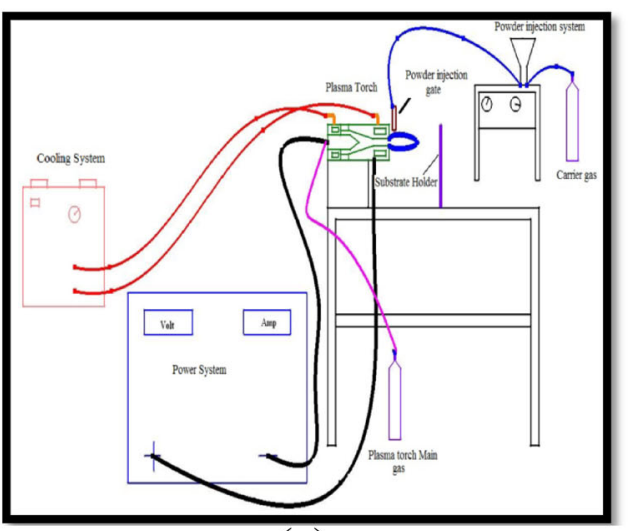

(a)

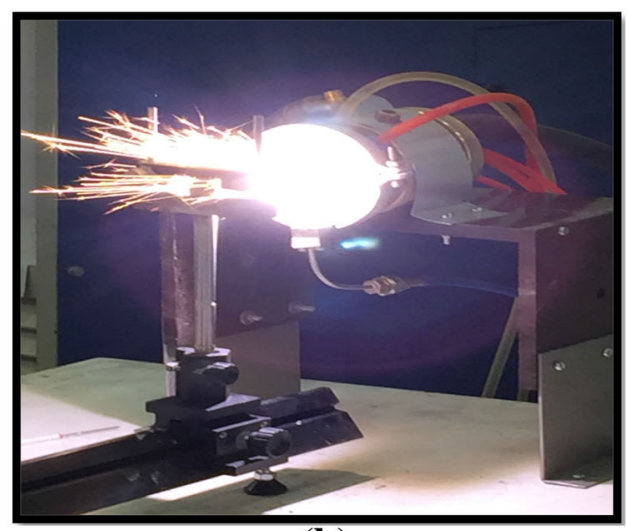

(b) 

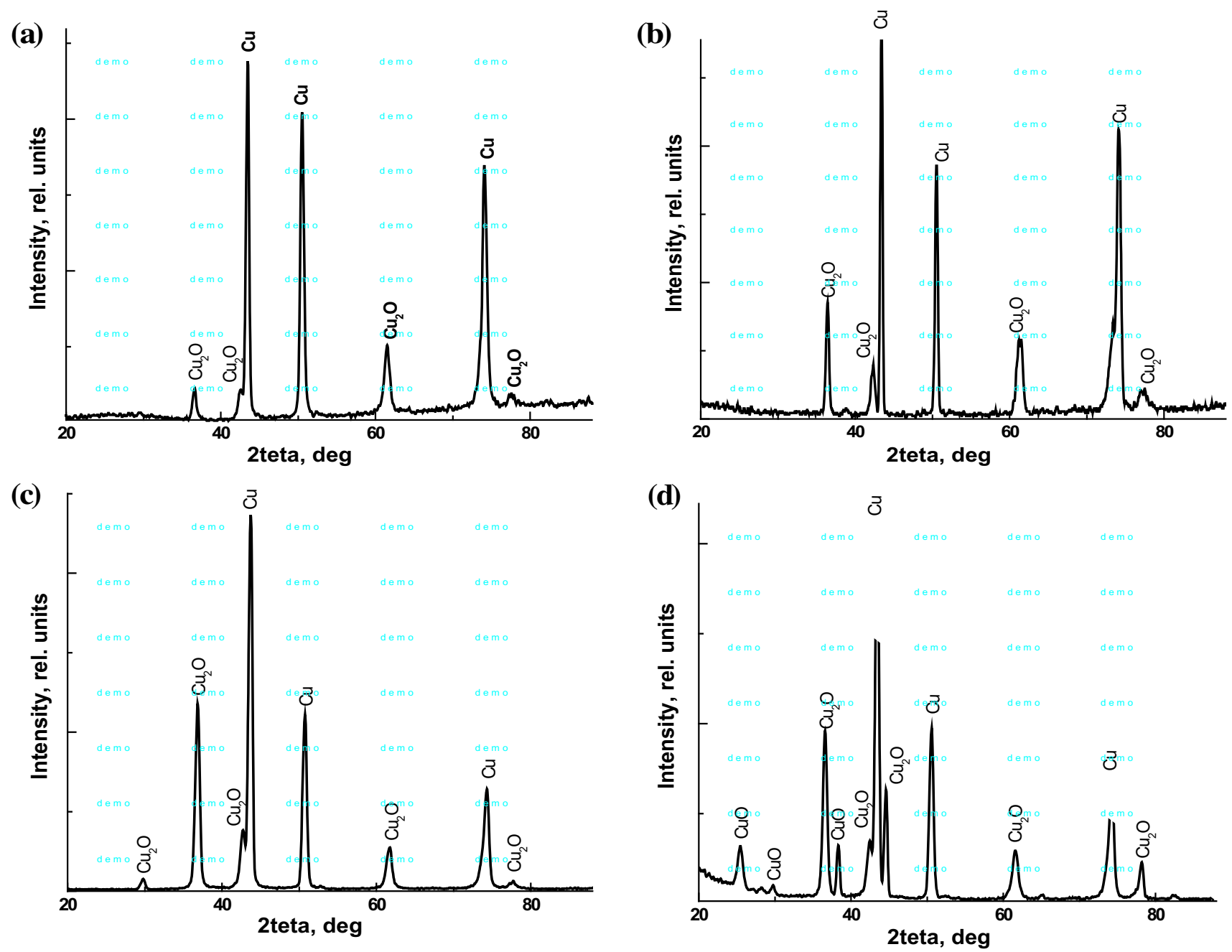

Fig. 2 XRD spectra of $\mathrm{Cu}$ coatings at SOD. a 150, b 175, c 200 and d $225 \mathrm{~mm}$

Using this relationship, we can determine how the ratio of weight percentages of copper oxide changes into that of copper. For this purpose, $W_{\mathrm{Cu}_{2} \mathrm{O}} / W_{\mathrm{Cu}}$ is considered as the ratio of weight percentage of copper oxide into that of copper, and by using the intensity of the most intense peaks of these two phases, which are located at $36.52^{\circ}$ (the most severe peaks of copper oxide) and $43.57^{\circ}$ (the most intense peaks of copper), we calculate the ratio. (It should be noted that the spectra of both phases were also examined for preferential orientation and preferential orientation was not observed in any of the coatings in a particular direction.)

$$
\left(\frac{I_{\mathrm{Cu}_{2} \mathrm{O}(\mathrm{a})}}{I_{\mathrm{Cu}(\mathrm{a})}}=0.12, \frac{I_{\mathrm{Cu}_{2} \mathrm{O}(\mathrm{b})}}{I_{\mathrm{Cu}(\mathrm{b})}}=0.26, \frac{I_{\mathrm{Cu}_{2} \mathrm{O}(\mathrm{c})}}{I_{\mathrm{Cu}(\mathrm{c})}}=0.47, \frac{I_{\mathrm{Cu}_{2} \mathrm{O}(\mathrm{d})}}{I_{\mathrm{Cu}(\mathrm{d})}}=0.43\right) .
$$

After calculation, it is found that the ratio of weight percentages of copper oxide to copper for coatings (a), (b), (c), and (d) are as follows:
$\frac{W_{\mathrm{Cu}_{2} \mathrm{O}(\mathrm{c})}}{W_{\mathrm{Cu}(\mathrm{c})}}>\frac{W_{\mathrm{Cu}_{2} \mathrm{O}(\mathrm{d})}}{W_{\mathrm{Cu}(\mathrm{d})}}>\frac{W_{\mathrm{Cu}_{2} \mathrm{O}(\mathrm{b})}}{W_{\mathrm{Cu}(\mathrm{b})}}>\frac{W_{\mathrm{Cu}_{2} \mathrm{O}(\mathrm{a})}}{W_{\mathrm{Cu}(\mathrm{a})}}$.

Increase in the proportion of weight percentages of copper oxide to copper from coating (a) to (c), in which SOD also increased, can be attributed to an increase of the interaction of copper particles with oxygen of the air due to the increased distance. But for coating at SOD $225 \mathrm{~mm}$, (d), which has the greatest distance from the nozzle, not only the ratio of weight percentage of copper oxide to copper is higher than that of (a) and (b), but also we see the presence of $\mathrm{CuO}$ peaks in the XRD spectrum of this coating.

To scan the cross section of the coatings, they are polished and mounted. SEM images of coatings at the standoff distances of 150, 175, 200 and $225 \mathrm{~mm}$ are shown in Fig. 3. These images show excellent adhesion between the substrate and coating at a distance of $175 \mathrm{~mm}$ and the coating is completely locked to the irregularities of 
Fig. 3 SEM images of $\mathrm{Cu}$ coatings at SOD. a 150, b 175, c 200 and d $225 \mathrm{~mm}$
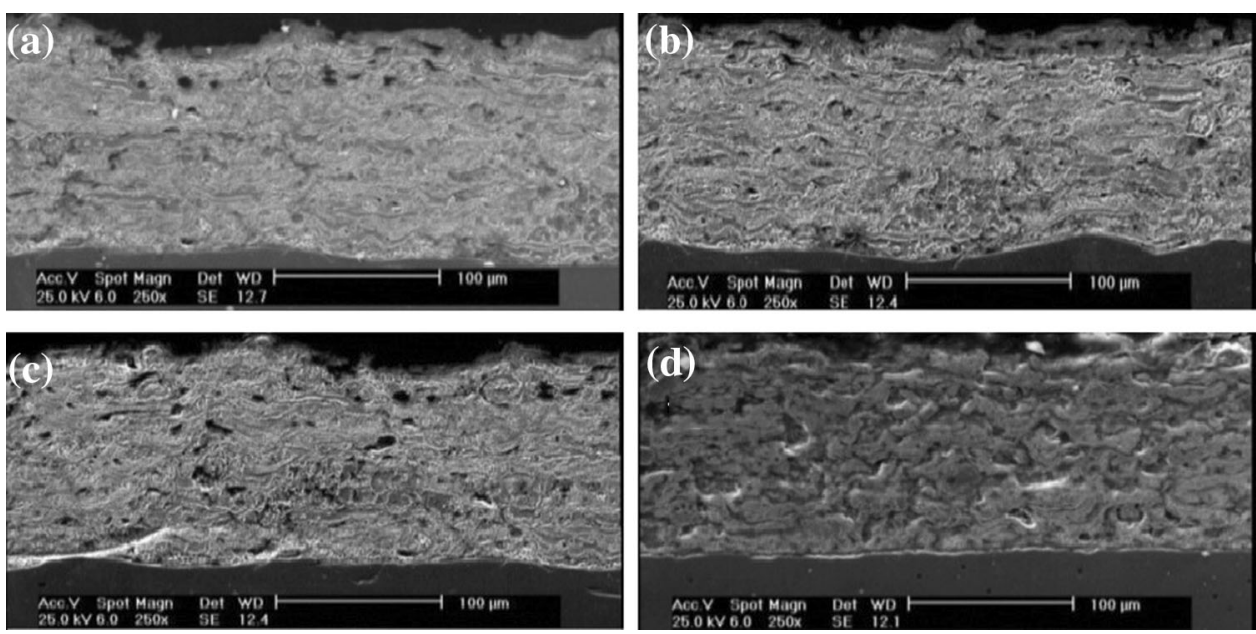

substrate, as seen in Fig. 3b. This property (adhesion) is later investigated also by TQC.

Using image analysis, the thicknesses of depositions with the measurement software are measured 110, 106, 100 and $92 \mu \mathrm{m}$, respectively. It can be said that the thickness of coatings decreases slightly by increasing SOD. Based on empirical and computational studies, the temperature of the plasma jet decreases along the torch axis with increase in SOD [15]. The powder particles have different sizes as seen in "Methods". In addition, to the energy of the plasma jet is reduced on heating the powder and its carrier gas. Therefore, the particles injected in the plasma jet appear in three states: fully molten, partially molten and solid, during flight and at the moment of impact. By increasing the SOD, because of greater drop in the particle surface temperature, the number of solid particles increases. The partial molten and solid particles may be fragmented and weakly connected to the coating and or are bounced when they encounter the surface of the substrate or accumulate as splats without forming the coating.

To detect the fine structure of the coatings, they are etched by a solution of ammonia $125 \mathrm{ml}$, hydrogen peroxide $250 \mathrm{ml}$ and distilled water $125 \mathrm{ml}$. The images suggest a layer structure for all coatings. Comparison of Fig. 3a-d confirms that by increasing SOD, the number of spherical particles (not melted) increases and the compactness of the structures decreases. As seen in Fig. 3a, b, at the distances 150 and $175 \mathrm{~mm}$, the lamellae are compressed. However at SOD $175 \mathrm{~mm}$, the lamellae are more regular and also wider than those formed at SOD $150 \mathrm{~mm}$. Because the molten particles after collision can flow well on the substrate and flatten sufficiently. At SOD $200 \mathrm{~mm}$, the lamellae are even but some voids appear in coating as shown in Fig. 3c. The voids are marked with black color. The air or the plasma gas dissolved in the liquid particles is trapped during impacting on the substrate and the splats are accumulated; therefore, the voids are formed. The voids located on the interface of the substrate coating and also between lamellae reduce the adhesion of the coating as verified by TQC. Figure $3 \mathrm{~d}$ indicates the heterogeneous structure at SOD $225 \mathrm{~mm}$, which has a lot of formless voids. In this structure, the lamellae are uneven and dissimilar. Because the lamellae created are exposed to insufficient heat of the plasma jet, they are less integrated with each other.

Due to the high temperature of the plasma jet, the powder particles are usually melted. Particles may overheat; the particle surface temperature exceeds its boiling point, and thus they evaporate. Molten particles may collide, stick together and agglomerate during flight at low stand-off distances. The liquid phase can react with oxygen of atmosphere in SOD. As the thermal diffusivity of the oxide layer of particle is significantly less than that of the metallic phase, the heat exchange between the particle and the plasma is decreased. During flight, the turbulence of the liquid phase destroys the surface layer of oxygen and spreads through the volume of the particle. In addition, during flattening and solidification of splats (and thereupon lamellae) before arrival of other particles, their upper surface is exposed to the oxygen of the atmosphere. As seen in Fig. 4 at more SOD, powder particles are exposed to more oxygen of the atmosphere which is marked gray. As previously concluded using quantitative phase analysis and mentioned under the results for XRD, the ratio of weight percentage of copper oxide to that of copper in the coatings increases. Consequently, the oxygen content increases too due to SOD increases.

The voids reduce the area of loading tolerance. They create a state of multilateral stress which concentrates the local pressure in their vicinity. As a result, more voids lead to less hardness. As seen in the fine structure of coatings, since larger grains do not match well with each other and more voids are formed in the coating, the cohesion between grains, particles, splats and lamellae decreases by 
Fig. 4 SEM images of $\mathrm{Cu}$ coatings at SOD. a 150, b 175, c 200 and d $225 \mathrm{~mm}$ and etched
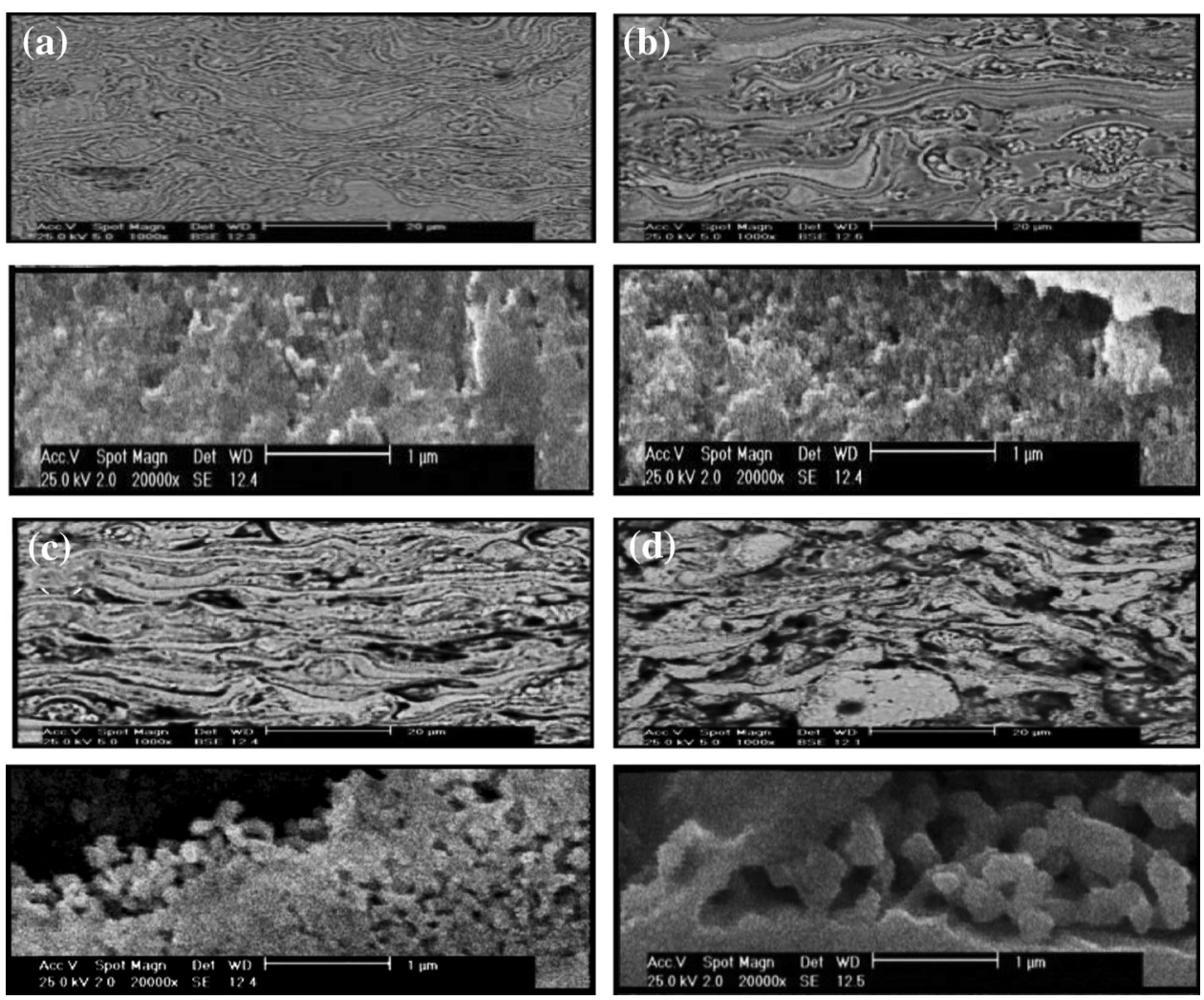

increasing SOD. The decrease of coating hardness by increasing SOD can be associated with increase in the size of grains inside the lamellae and also voids. The percent of voids in coatings for different stand-off distances is evaluated by image analyzer software and is 2, 3.09, 9.98 and $22.3 \%$ respectively.

The specific dissection of the etched lamellae with more magnification as seen in Fig. 4 (with no Alphabet letters) authenticates the grain structure inside each of the lamellae. The grains grow perpendicular to the direction of lamellae progress. As seen in Fig. 4, the size of the grains is sub-micrometer. At more distances, grains are less ordered and larger. Therefore, more and larger voids emerged in the coatings. At distances of 150 and $175 \mathrm{~mm}$, the grains are cohesive and nearly coaxial. Figure 4 shows that by increasing the distance, the binding between grains decreases and the space between grains increases. This space depends on the cooling rate of splats which is inversely proportional to splat thickness or its square [9]. The bigger grains are seen at SOD $225 \mathrm{~mm}$ (Fig. 4d). The mean sizes of grains for different stand-off distances are evaluated by image analyzer software which is $80,85,110$ and $230 \mathrm{~nm}$, respectively. This means when stand-off distance increases, the grains size also increases.

The basis of the Vickers hardness test is the penetration of the diamond into the surface of the coating. The diamond indenter is in the form of a prism with a square rule.
Hardness is the ratio of applied load to the immersion area. The images of Vickers hardness tester for each of coating is seen in Fig. 5.

The Vickers tests values confirm that the SOD influences the hardness of the coatings. The hardness of the coating formed at SOD $150 \mathrm{~mm}$ is $164 \mathrm{HV}_{0.1}$. When SOD increases from 150 to $175 \mathrm{~mm}$, the hardness increases to $165 \mathrm{HV}_{0.1}$ and shows no significant alteration. By more increment of SOD to 200 and $225 \mathrm{~mm}$, the hardness of the coatings drops from 164 to 159 and $144 \mathrm{HV}_{0.1}$, respectively. These values and their relations with SOD are seen in Fig. 6. The hardness of copper coatings obtained by plasma spraying is more than the hardness of annealed bulk copper, which may be associated with inclusion in the lamellae of oxygen [12]. Although by increasing the SOD, the amount of oxygen increases in the coatings and it is expected to increase the hardness of coatings [12], in these depositions the hardness of coatings decreases by increasing SOD, which may be due to decrease of particle temperature [5] and thereupon increasing of voids of coating.

In the test of adhesion, after peeling off the glue, the amount of the remainder coatings is compared with the ASTM standard pattern. The images of the coatings' remainder by TQC for each of the coatings are seen in Fig. 7. They are classified into $4 \mathrm{~B}, 5 \mathrm{~B}, 4 \mathrm{~B}$ and $1 \mathrm{~B}$, respectively. The increment of SOD decreases the adhesion strength between the coating and substrate as seen in 
Fig. 5 Images of Vickers hardness tester with magnification 400 for $\mathrm{Cu}$ coatings at SOD. a 150 , b 175 , c 200 and d $225 \mathrm{~mm}$
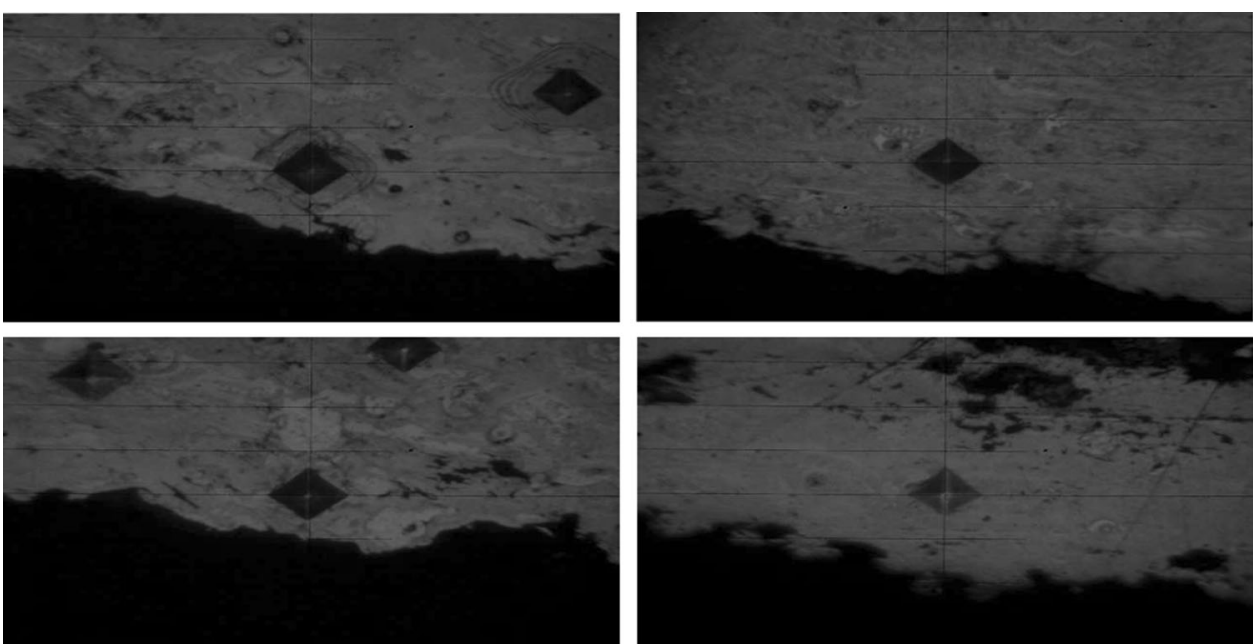

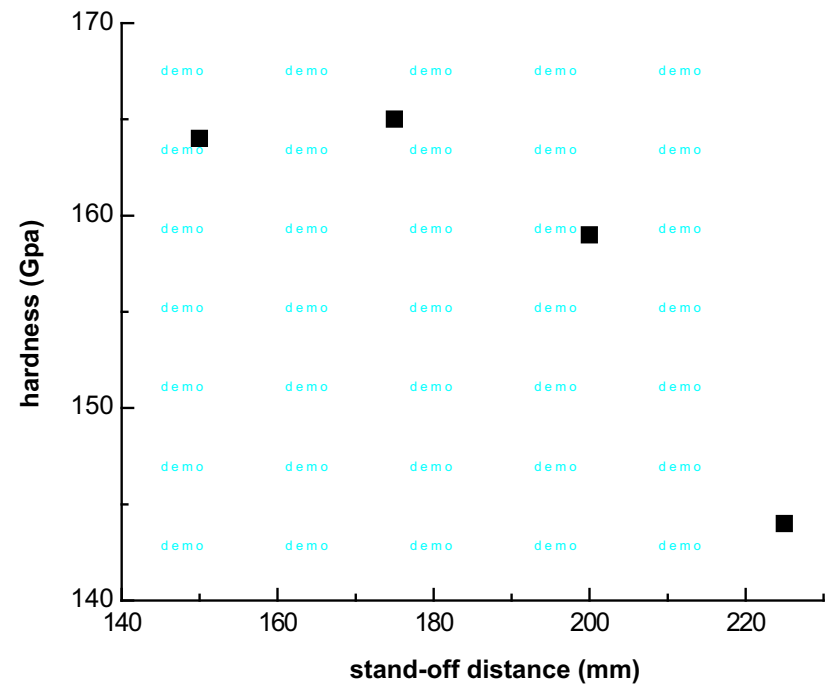

Fig. 6 Relation between coating hardness and SOD

Fig. 8. At high stand-off distances due to decrement of surface temperature of particles, they will not have sufficient temperature for good adhering to the substrate and also splats accumulate. The molten particles are cooled by moving away from the plasma jet and scattering into the environment. Furthermore, at a very short spray distance, the adhesion strength is low due to thermal stress in the output region of the plasma jet and its mixing with the atmosphere. In contrast, at a critical distance $(175 \mathrm{~cm})$, the best adhesion strength is achievable.

\section{Conclusion}

Copper coatings are prepared using the handmade atmospheric plasma spraying (APS) system at different standoff distances onto the stainless steel $316 \mathrm{~L}$ substrate. Here, the system works under the fixed spray conditions and the only changing parameter is the stand-off distance (SOD). It is proven that the fine structure of the coating depends on SOD. By increasing SOD, the size of grains and the space between grains in the lamellae increase and the content of oxygen in the coating also increases. More and larger voids emerge in the deposition. Therefore, the cohesion between lamellae and the coating hardness decrease. Moreover, adhesion strength also decreases. At a critical distance, we achieved the highest degree of adhesion in ASTM pattern
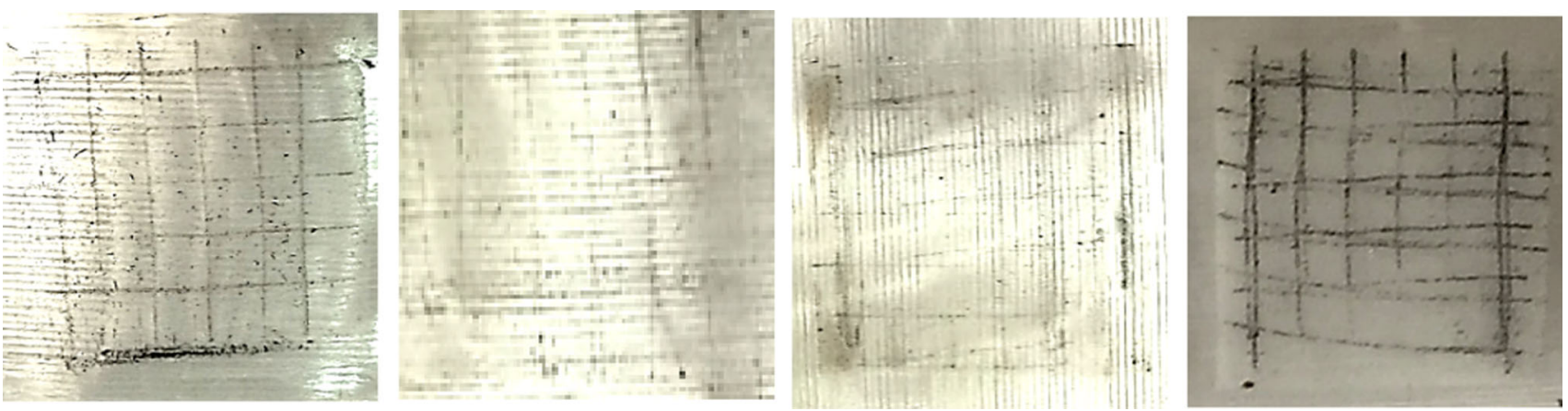

Fig. 7 Images of coatings' remainder by TQC for coatings at SOD. a 150, b 175, c 200 and d 225 mm 


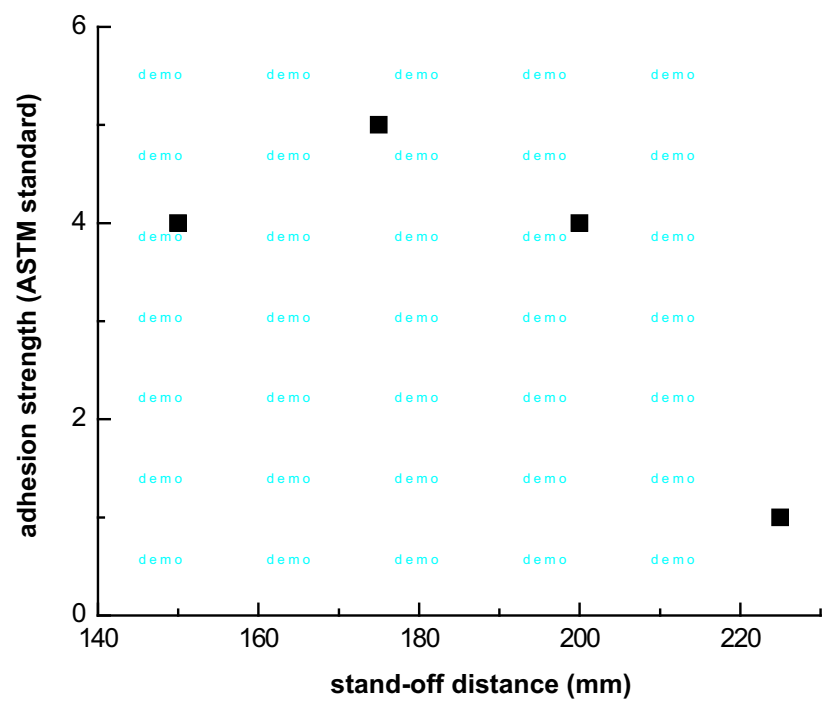

Fig. 8 Relation between adhesion strength of coating and SOD

classification. The SOD is one of the important parameters for creating a coating with excellent mechanical properties.

Open Access This article is distributed under the terms of the Creative Commons Attribution 4.0 International License (http://creative commons.org/licenses/by/4.0/), which permits unrestricted use, distribution, and reproduction in any medium, provided you give appropriate credit to the original author(s) and the source, provide a link to the Creative Commons license, and indicate if changes were made.

\section{References}

1. Li, C.J., Li, J.L.: Evaporated-gas-induced splashing model for splat formation during plasma spraying. Surf. Coat. Technol. 184, 13-23 (2004)

2. Sarikaya, O.: Effect of the substrate temperature on properties of plasma sprayed $\mathrm{Al}_{2} \mathrm{O}_{3}$ coatings. Mater. Prot. 26, 53-57 (2005)

3. Karthikeyan, J., Berndt, C.C., Tikkanen, J., Reddy, S., Herman, H.: Plasma spray synthesis of nanomaterial powders and deposits. Mater. Sci. Eng. A 238, 275 (1997)
4. Vessey, A.: Antimicrobial copper touch surfaces. Health Manag. 4, 15 (2015)

5. Li, Chang-Jiu, Sun, Bo: Microstructure and property of microplasma-sprayed $\mathrm{Cu}$ coating. Mater. Sci. Eng. A 379, 92-101 (2004)

6. Janisson, S., Vardelle, A., Coudert, J.F., Meillot, E., Pateyron, B., Fauchais, P.: Plasma spraying using Ar- $-\mathrm{He}_{2} \mathrm{H}_{2}$ gas mixtures. Therm. Spray Technol. 8, 545 (1999)

7. Li, C.-J., Ohmori, A.: Relationship between the microstructure and properties of thermally sprayed deposits. Therm. Spray Technol. 11, 365 (2002)

8. Prystay, M., Gougeon, P., Moreau, C.: Structure of plasmasprayed zirconia coatings tailored by controlling the temperature and velocity of the sprayed particles. Therm. Spray Technol. 10, 67 (2001)

9. Christoulis, D.K., Pantelis, D.I., Fabregue, N., Borit, F., Guipont, V., Jeandin, M.: Effect of substrate temperature and roughness on the solidification of copper plasma sprayed droplets. Mater. Sci. Eng. A 485, 119-129 (2008)

10. Yang, K., Liu, M., Deng, C.: Adhesion strength of $\mathrm{Cu}$ coating on substrate at different temperature. Surf. Eng. 30(11), 814-821 (2014)

11. Planche, M.P., Betoule, O., Coudert, J.F., Grimaud, A., Vardelle, M., Fauchais, P.: Fauchais performance characteristics of a low velocity plasma spray torch. In: Berndt, C.C., Bernecki T.F. (eds.) Proceedings of the 5th National Thermal Spray Conference, pp. 81-87. ASM International, Materials Park, OH (1993)

12. Rezaei, F., Saviz, S., Ghoranneviss, M.: Medical equipment biocapability processes using the atmospheric plasma-sprayed titanium coating. J. Theor. Appl. Phys. (2018). https://doi.org/10. 1007/s40094-017-0269-5

13. Goudarzi, M., Saviz, Sh, Ghoranneviss, M., Salar Elahi, A.: Medical equipment antiseptic processes using the atmospheric plasma sprayed copper coatings. J. X-ray Sci. Technol. 25, 479-485 (2017)

14. Karlak, R.F., Burnett, D.S.: Quantitative phase analysis by X-ray diffraction. Anal. Chem. 38(12), 1741-1745 (1966)

15. Selvan, B., Ramachandran, K., Sreekumar, K.P., Ananthapadmanabhan, P.V.: Numerical and experimental studies on DC plasma spray torch. Vacuum 84(4), 444-452 (2009)

\section{Publisher's Note}

Springer Nature remains neutral with regard to jurisdictional claims in published maps and institutional affiliations. 